\section{Predicting HCV drug response}

\section{By Lauren Martz, Staff Writer}

Duke University researchers have identified an $I L-28 B$ polymorphism that could help predict a patient's response to $\mathrm{HCV}$ drugs. ${ }^{1}$ The findings also could point toward the identification of new therapeutics for patients who don't respond to standard therapy. Schering-Plough Corp. holds rights to the biomarker and is considering whether to partner the discovery.

$\mathrm{HCV}$ affects 170 million people worldwide and can cause chronic liver diseases including cirrhosis and liver cancer. Standard treatment involves a 48-week course of peginterferon- $\alpha$ $2 b$ (PegIFN- $\alpha-2 b)$ alone or in combination with ribavirin. The regimen has serious side effects including depression, fatigue and flu-like symptoms, ${ }^{2}$ and-at best-only works about half the time.

According to David Goldstein and John McHutchison, members of the Duke team, patient responses are also inconsistent across races, ranging from $20 \%-25 \%$ among African Americans to $38 \%-45 \%$ among European Americans infected with $\mathrm{HCV}$ genotype I.

Mingjun Huang, head of virology at Achillion Pharmaceuticals Inc., told SciBX that "due to the long-term therapy and also significant side effects associated with the current standard of care, knowing the response of any particular patients to standard of care before initiating the therapy is very much desired. If a diagnostic test predicts that a sustained virologic response is unlikely to be achieved for a patient, it is probably better for the patient to wait until better drugs become available, especially if his/her liver damage is not severe."

In a paper published in Nature, Goldstein and colleagues identified a polymorphism near the $I L-28 B$ (IFNL3) gene that was significantly associated with a positive response to standard therapy for HCV.

Goldstein is director of the Center for Human Genetic Variation at Duke's Institute of Genome Sciences and Policy.

The researchers performed a genomewide association study on more than 1,600 HCV patients from the IDEAL (individualized dosing efficacy vs. flat dosing to assess optimal pegylated interferon therapy) study, plus 67 additional patients from a separate prospective study, to identify polymorphisms associated with treatment response.

The team found that a sustained viral response (SVR) - the absence of detectable virus at the end of the follow-up period-was associated with an rs 12979860 polymorphism on chromosome 19 , which is 3 kilobases upstream of the $I L-28 B$ gene.

A genotype dubbed CC was associated with a twofold greater SVR rate than a genotype called TT. This finding may explain the differences in response across patient populations, as the team found that the CC genotype is more common in European Americans than in African Americans.

Also, the $I L-28 B$ genotype proved to be a better predictor of treatment response than baseline viral load.

Indeed, McHutchison, an author on the paper, said the results show that the $I L-28 B$ genotype is a stronger predictor of patient response to treatment than any other available measure. "Since this discovery is a stronger predictor of favorable treatment responses than all other baseline factors, we have a very accurate ability to predict likelihood of treatment response before patients start therapy," he told SciBX.

McHutchison is associate director of the Duke Clinical Research Institute, director of the GI/hepatology research program and professor of medicine in the Division of Gastroenterology.

Goldstein did note that the findings should not necessarily rule out therapy for patients with poorer response genotypes. " $I L-28 B$ genotype would be one factor among many that clinicians could use" to make the best treatment decision for individual patients, he said.

"Depending on their clinical characteristics, such as degrees of liver fibrosis and symptoms, a decision could be taken to delay therapy until new add-on therapies become available or patients would still receive therapy, but the patient and provider would have a much clearer understanding before the treatment of the likelihood of success," according to the Nature authors.

"Treatment strategies for patients with less favorable $I L-28 B$ genotypes will perhaps need to be studied in trials and customized according to the duration and number of drugs they should receive to achieve the best response possible," McHutchison told SciBX.

Huang said it should not be technically hard to create a diagnostic for $I L-28 B$ genotype. "Any commercial entity that is now in the business for genetic testing utilizing DNA sequencing technology can do the test as of today," she said.

Instead, Huang said, the challenge will be "to confirm clinical validity. For example, the association between mutations in breast cancer 1 early onset (BRCA1) and a predisposition to breast and/or ovarian cancer was demonstrated in 1995, but identification of clinical benefit from genetic testing remains an issue currently being addressed in several ongoing, prospective, population-based studies."

"Consequently," she said, "government agencies and professional societies either do not recommend the test or only do so to those women whose family history is associated with an increased risk for deleterious mutations in the BRCA1 or BRCA2 genes." 


\section{TARGETS \& MECHANISMS}

Thus, said Huang, the first step is to replicate the findings. "The data per se are solid, but as with any epidemiology study, a study with another population of patients is needed."

\section{Finding a new intervention}

Although studies that replicate the findings in the Nature paper might lead to an effective diagnostic, understanding the underlying biology of the diverse patient responses could help identify new therapies for HCV.

"There is some basic biology that needs to be done in order to understand how the $I L-28 B$ polymorphism influences viral control," said Goldstein. "Once that is done, we will have a clearer view of whether there is a therapeutic direction available to capitalize on these observations. Can we work out a way to make the poor-response genotype individuals more like the good-response genotype ones? In principle, it seems this could be achievable through some kind of new combination therapy."

Achillion and Gilead Sciences Inc. are developing ACH-1625, a small molecule of HCV NS3 protease that is in Phase I testing. Huang told SciBX that the efficacy of immune modulators such as interferon is always associated with host gene variation, whereas targeted approaches such as Achillion's are directed at the virus itself, possibly eliminating the variable response among patients.

Schering-Plough spokesperson Robert Consalvo told SciBX that the company owns rights to the biomarker. He said the IP is available for licensing and the company might be interested in partnering the biomarker.

Schering-Plough markets several HCV therapeutics including Intron A interferon alfa-2b, Rebetol ribavirin and PegIntron/Rebetol combination therapy. Schering-Plough is being acquired by Merck \& Co. Inc.

Martz, L. SciBX 2(34); doi:10.1038/scibx.2009.1298

Published online Sept. 3, 2009

\section{REFERENCES}

1. Ge, D. et al. Nature; published online Aug. 16, 2009; doi:10.1038/nature08309

Contact: David Goldstein, Duke University, Durham, N.C. e-mail: d.goldstein@duke.edu

2. Okanoue, T. et al. J. Hepatol. 25, 283-291 (1996)

\section{COMPANIES AND INSTITUTIONS MENTIONED}

Achillion Pharmaceuticals Inc. (NASDAQ:ACHN), New Haven, Conn Duke University, Durham, N.C.

Gilead Sciences Inc. (NASDAQ:GILD), Foster City, Calif.

Merck \& Co. Inc. (NYSE:MRK), Whitehouse Station, N.J. Schering-Plough Corp. (NYSE:SGP), Kenilworth, N.J. 